\title{
Escola Waldorfiana sob a óptica de uma pesquisa intertransdisciplinar
}

\author{
Ana Cristina Souza dos Santos * \\ Helena Corrêa de Vasconcelos ${ }^{* *}$ \\ Akiko Santos ${ }^{* * *}$
}

\section{Resumo}

O presente trabalho foi resultado da pesquisa realizada em uma escola pública waldorfiana, situada na cidade de Nova Friburgo-RJ. O diálogo com esse espaço escolar inovador foi marcado por visitas, estudo de análise documentária e produção de textos, explicitando distintas dimensões dessa escola. O estudo teve como principal objeto temático a organização curricular integradora, Waldorfiana que, sob a óptica de uma pesquisa intertransdisciplinar, mantém a preocupação em produzir conhecimento dessa mesma natureza - com fundamentos oriundos da literatura e de uma realidade escolar específica, onde pulula o debate sobre a questão escolar do currículo. Neste texto buscou-se apresentar os caminhos da pesquisa, seu referencial teórico-metodológico, enfatizando as formulações teóricas de Edgar Morin, Ivor Goodson e Rudolf Steiner que sustentam a concepção de organização curricular na perspectiva teórica integrativa e integradora. Este documento procura também oferecer visibilidade às práticas desenvolvidas, em sintonia com o projeto waldorfiano que norteia essa escola, enquanto produto de observações vicárias lá efetuadas, trazendo primeiramente a visão geral do projeto político pedagógico das instituições e, posteriormente, concentra-se nas narrativas eleitas, oriundas de suas observações vicárias, a fim de evidenciar a trajetória de uma escola waldorfiana, dando visibilidade a peculiaridades institucionais que lhe distingue da escola tradicional.

Palavras-chave: Pedagogia Waldorf, Organização Curricular, pesquisa intertransdisciplinar.

\footnotetext{
* Doutora em Química (2002). Mestre em Química Orgânica (1991) Graduada em Licenciatura em Ciências, Habilitação em Química. Professora Associada IV da Universidade Federal Rural do Rio de Janeiro. Professora do Mestrado Acadêmico em Educação Agrícola/UFRRJ. Coordenadora do Mestrado Profissional em Educação em Ciências e Matemática do Instituto de Educação da UFRRJ. E-mail: anacrissantos.ufrrj@yahoo.com.br

** Mestre e Doutora em Educação pela Universidade Federal do Rio de Janeiro. Graduada em Pedagogia. Professora Adjunto 4 da Universidade Federal Rural do Rio de Janeiro. E-mail: lenaba@uol.com.br

*** Doutora em Educação pela Universidade Metodista de Piracicaba. Mestre em Educação de Adultos pela Universidade Federal da Paraíba (1985). Graduada em Licenciatura em Letras pela Universidade de Brasília (1969). Professora aposentada da Universidade Federal Rural do Rio de Janeiro. Membro fundador do LEPTRANS - Laboratório de Estudos e Pesquisas Transdisciplinares/UFRRJ. E-mail: akiko.santos@ gmail.com
} 


\title{
Waldorfiana school under an optical search inter transdisciplinary
}

\begin{abstract}
The work was the result of research conducted in a waldorfiana public school in the city of Nova Friburgo-RJ. The dialogue with this innovative school environment was marked by visits, documentary analysis study and production of texts, highlighting different dimensions of this school. The study had as main theme object integrative curricular organization, Waldorfiana, from the perspective of an intertransdisciplinar research. This research is concerned in producing knowledge of that nature - on grounds derived from the literature and from a specific school reality, where there is growing debate about school curriculum issue. In this paper we tried to present the paths of research, its theoretical framework, emphasizing the theoretical formulations of Edgar Morin, Ivor Goodson and Rudolf Steiner that underpin the design of curricular organization in integrative theoretical perspective. This document seeks to provide visibility to the practices developed, in line with the waldorfiano project that guides this school, as a product of vicarious observations made there, first bringing the overview of the political pedagogical project of the institutions and, subsequently focuses on elected narratives derived from their vicarious observations in order to show the trajectory of a waldorfiana school, giving visibility to institutional peculiarities that distinguish it from traditional school.

Keywords: Waldorf Education, Curriculum Organization, inter transdisciplinary research,
\end{abstract}

\section{Introdução}

A origem do trabalho é marcada pelo problema da organização curricular enquanto artefato e fator determinante dos diversos desdobramentos seguintes na vida escolar, em geral e estudantil, em particular, em que pese o seu aparente isolamento despretensioso, sobretudo quando estruturado na forma disciplinar que predomina quase soberana sobre outras possibilidades organizativas de natureza integradora.

Ainda hoje vige em diferentes continentes a hegemonia da disciplinarização, pondo em evidência toda a lógica da fragmentação própria de um projeto de modernidade oriundo do século XVII, a despeito dos clamores científicos, das determinações legais e das demandas contextuais por uma escola regida pela inteligência complexa - tal como sugere a preceptora proposta pedagógica Waldorfiana, ainda que muito adiante de seu tempo, para subsidiar vivências de amplas relações teóricas e práticas.

Rudolf Steiner introduziu a Pedagogia Waldorf em 1919, na cidade de Stuttgart - Alemanha, inicialmente em uma escola para os filhos dos operários da fábrica de cigarros Waldorf-Astória, a pedido dos próprios pais. Foi a primeira experiência de Steiner em um contexto escolar, marcado por grandes inquietações sobre os problemas que perturbavam o mundo do trabalho fabril de seu tempo, dentre os quais declara: 
"feminismo, problemas educacionais e escolares, problemas relacionados ao direito, à saúde, entre outros" (STEINER, 1969).

A problemática que justificou e sustentou a pesquisa está ligada, sobretudo, a preocupações tanto com a ampla predileção pela organização curricular disciplinarizante, quanto pela simultânea secundarização - quase silenciamento e marginalização, de experiências escolares que sustentem teorias e práticas de inter/trans/disciplinaridade como princípio educativo organizacional, chamados a presidir ou reger o conjunto de conhecimentos e práticas estruturantes do cotidiano escolar, priorizados para circular no contexto escolar e/ou universitário.

Ao fazerem opção por este ou por aquele modo de organizar o currículo as pessoas (físicas e/ou jurídicas) - consciente e/ou inconscientemente, voluntária ou involuntariamente, neste ato, já pressupõem um conjunto de ações que são duradouramente, quase irreversíveis - pois ficarão ativadas até o momento em que seja instituída uma nova opção político-filosófica, inclusive epistemológica, que a subverta. Mas essa outra maneira organizacional, também exigirá um novo "recomeço" na trajetória da instituição e das pessoas a ela ligadas, de alguma maneira, pois a velha organização se nega a morrer e a nova demora a se instaurar.

Para se instituir um rol expressivo de antecedentes e desdobramentos ligados ao modo de organização curricular estará presente, interferindo na vida da instituição em geral e, em particular, das pessoas a ela interligadas, a exemplo de: (a) escolha/ definição do espaço físico que sediará o empreendimento educativo; (b) planejamento e construção das acomodações das pessoas, no espaço físico destinado a realização das atividades na instituição; (c) especificações de todo o acabamento, o mobiliário fixo ou não, incluída a decoração estética; e (d) arranjos finais estéticos e pedagógicos norteadores do que será feito o cotidiano institucional. Tudo isso em consonância com as exigências e particularidades de um Projeto Políticopedagógico - cujo cérebro e coração, nele contido, residem na proposta curricular a ser vivenciada naquele espaço.

Do ponto de vista epistemológico a opção implica, sobretudo, uma práxis específica, acionando, simultaneamente, sobretudo, as relações teoria \& prática, todo \& partes, singular \& plural, que, colocadas como pontos de partida no processo de escolarização repercutirão em toda a vida cotidiana das pessoas nela envolvidas. Ou seja, há interferências relacionadas, sobretudo, ao âmbito do projeto político-pedagógico posto em curso, implicando: (a) provimento de recursos materiais e humanos sintonizados com a lógica e a dinâmica pedagógica instituída pelo currículo (pre)scrito, mesmo que apenas presumido; (b) realização de estudos de revisões e avanços relativos a proposta pedagógica imaginada, desenhada; (c) manutenção de relação ativa e estreita 
entre o sistema de organização dos estudantes e a natureza integrativa ou fragmentária do projeto educativo em pauta, pois o sistema de organização estudantil é fundamental na sustentação do processo de escolarização comprometido tanto com projetos de integração, quanto com projetos de fragmentação dos conhecimentos - ainda que os desdobramentos disso sejam sensivelmente sintonizados com cada uma das perspectivas epistemológicas sustentadas que se leve em consideração; e (d) acompanhamento "vigilante" do cotidiano escolar para manter ativa a lógica curricular presumida, desejada - voluntária ou involuntariamente pelo projeto posto em curso, pelos grupos a ele integrados, a partir de algum lugar hierárquico de poder.

Portanto, o processo de organização curricular não é algo simples e tranquilo, é antes complexo e problemático, escondendo em si uma força determinante quase enigmática - que só após a opção feita por este ou aquele princípio epistemológico poderá ser plenamente descortinada nos seus desdobramentos. Trata-se de um pilar com duplo modus operandi de trabalho com o conhecimento científico eleito para circular no âmbito da escola e/ou da universidade. Um deles privilegia e institui o acesso através das disciplinas isoladamente consideradas e o outro contempla as disciplinas articuladas entre si, de diferentes maneiras. Em ambos os casos existe estratégias correlatas apropriadas para consolidar o projeto curricular "eleito" trazendo a marca quase irremediável da visão de mundo.

Não sem razão Morin (2008, p. 60) foi inspirado e nos inspira a eleger a organização como um dos pilares de seu projeto de complexidade - a partir da visão de que tudo o que é organização concerne à vida biológica e antroposociológica; mas ele nos adverte que não se trata de

(...) uma alternativa de exclusão entre, de um lado, a desordem e, de outro, a ordem e a organização, mas como uma questão de ligação. A partir daí, a gênese de partículas materiais, núcleos, átomos, moléculas, galáxias, estrelas, planetas é indissociável de uma diáspora e de uma catástrofe; então há uma relação crucial entre a explosão da desordem, a constituição da ordem, o desenvolvimento da organização.

Evidente que a fala do autor se interliga a sua profícua análise da physis - objeto de estudo do autor, a partir de relações entre componentes ou indivíduos que produz uma unidade complexa ou sistema, dotado de qualidades desconhecidas quanto aos componentes ou indivíduos. Portanto, a fala não se refere de modo direto, ao sistema educacional, mas a pressupostos basilares de toda a obra que se interliga a tal enunciado. 
Importa agora assinalar que a presente pesquisa foi originada de múltiplos fatores intercomplementares, ligados a organização, abrangendo as sociedades e as instituições que denunciam insatisfação com o modelo de escola ainda vigente no mundo que, replica o legado fragmentário do projeto de modernidade, com ampla mediação curricular - artefato organizacional estruturante desse modelo, que precisa ser repensado, revisado, re-inventado.

Ora, ao que parece, a fase em que o projeto de modernidade alimentava a fragmentação curricular já foi superada, inclusive com respaldo da legislação brasileira que abriu a possibilidade de novos e flexíveis formatos curriculares que conjuguem o disciplinar com o inter e o trans disciplinar; de maneira que hoje, já vigoram experiências escolares (embora quase marginalizadas) que trabalham com diferentes formas de organização curricular: temas geradores, temas transversais, problemas, projetos, centros de interesse - que são estudos de natureza etnográfica, naturalística.

O projeto de modernidade faliu e sucumbiu, conforme evidenciam com riqueza de materialidade discursiva e não-discursiva, muitos leitores das realidades do mundo, desde os anos 1980, a exemplo de: Anderson (1995), Jameson (1993,1996), Bauman (2008), Ianni (1995), Hobsbawm (1996), então, por que a escola se mantém alheia ao mundo que a cerca, ignorando que não é ilha apartada da sociedade que lhe mantém em amplos sentidos?; Por que defender uma concepção teórica comprometida com ações escolares que priorizem processos de organização curricular integrados, intertransdisciplinares, quando no sistema escolar vigente predominam práticas centradas na disciplinaridade fragmentada? Que argumentos justificam a hegemonia da escolarização fragmentada, em sua organização curricular, em detrimento da escolarização totalizante, nas vozes de ocupantes de postos-chave decisórios em município fluminense que dispõe dos dois tipos epistemológicos de escola? A partir de distintos lugares ou histórias de vida, de envolvimento, participação e de dizer sobre a experiência de escolarização totalizante, que argumentos são apresentados para justificar a necessidade da organização escolar totalizante, em detrimento da escolarização fragmentada?

\section{Os caminhos da pesquisa}

Estas foram algumas das questões que se conseguiu registrar dentre aquelas que perpassaram os debates durante a pesquisa, entretanto, face às condições objetivas de trabalho, o estudo se delimitou a busca de resposta para três questões básicas seguintes: 1) Que contribuições a proposta (moriniana) de complexidade pode dar para 
a leitura crítica da escola de hoje e a tessitura de subsídios ao emergir de escolas comprometidas com os princípios e categorias teóricas desse projeto epistemológico?; 2) Será possível proscrever o currículo prescrito (goodsoniana), em favor de uma escola movida pela reconstrução ativa, crítica, criativa?; 3) Até que ponto uma escola que alia teoria e prática inter/trans/disciplinar se articula com o projeto steineriano? E com as aspirações de um currículo como narrativa?

Se a disciplinaridade na organização curricular acabou, em seu movimento histórico, gerando uma escola que se encontra em séria e prolongada crise - que a marca como instituição decadente, desajustada dos interesses e das necessidades sociais contemporâneos, nas quais - pesquisas revelam que as crianças pouco aprendem do conteúdo formalmente veiculado nas salas de aula e que esta instituição já "está obsoleta" (Semler et al, 2004, p. 11), a aposta ou hipótese de trabalho é que é possível reverter o quadro de descontentamento com a lógica organizacional fragmentária da disciplinaridade, em favor de práticas curriculares integradas de escolarização intertransdiciplinar, desde que seja dada visibilidade mais ampla a experiências desta natureza epistemológica, sobretudo a partir de estudos, pesquisas e debates sobre experiências escolares hoje minoritárias, marginais, carentes de expectativa de amplificação das vozes que falem a seu favor.

É preciso ampliar, difundir, especialmente, no contexto dos cursos de formação de professores o pressuposto de que há necessidade das escolas exercerem uma autocrítica, vislumbrando a possibilidade de se refazerem como instituições que podem servir a sociedade proscrevendo o currículo prescritivo, de modo flexível, aberto, embora sempre crítico.

Do ponto de vista teórico a pesquisa manteve ativo o diálogo, sobretudo, com autores que discutem teoricamente questões relacionadas aos eixos conceituais básicos emergentes e inscritos na problemática e nos objetivos de estudo: (a) organização, sistemas e inter-relações - ordem/desordem, simples/complexo; (b) escola, currículo - formas de organização curricular - disciplinaridade/intertransdisciplinaridade; e (c) fontes dos saberes escolares - teoria/prática instituídas.

A linha teórico-metodológica de construção, envolveu dois grandes mo(vi) mentos dialógicos articulados: por um lado, com a literatura correlata e, por outro, a análise documental norteadora de experiências concretas de adoção de uma pedagogia complexa, totalizante, integrada, integradora - supostamente intertransdisciplinar, na perspectiva de capturar nelas suas virtudes, problemas e encaminhamentos de solução, principalmente como currículo escrito para ser vivenciado. Nessa perspectiva o estudo foi realizado através do método de pesquisa qualitativo, nos termos em que 
Hübner (2004), Creswell (2010) e Triviños (2007), que fazem eco a Denzin e Lincoln (2007, p. 390) - que concebem o método qualitativo como

(...) campo interdisciplinar, transdisciplinar e, às vezes, contradisciplinar, que atravessa as humanidades, as ciências sociais e as ciências físicas. A pesquisa qualitativa é muitas coisas ao mesmo tempo. Tem um foco multiparadigmático. Seus paraticantes são suscetíveis ao valor da abordagem de múltiplos métodos, tendo um compromisso com a perspectiva naturalística e a compreensão interpretativa da experiência humana. Ao mesmo tempo trata-se de campo inerentemente político e influenciado por múltiplas lealdades éticas e políticas.

No que concerne às técnicas e aos instrumentos de investigação, cumpre antecipar a noção defendida por Denzin e Lincoln (2007, p. 392) segundo a qual embora tenha aliançado com exigências históricas contemporâneas, a pesquisa qualitativa recebe influências da já antiquada etnografia positivista, pois “(...) as estratégias e as técnicas básicas dos estudos de caso, das etnografias, da observação, das entrevistas e da análise textual ainda formam a base da pesquisa" desse tipo, no momento atual".

Edgar Morin, Ivor Goodson e Rudolf Steiner: três projetos teóricos que integram a concepção de organização curricular integradora.

Para sustentar o estudo foram utilizados três projetos teóricos convergentes para romper com a escola fragmentária, dissociada de interesses e necessidades social, em favor de uma escola integrada/integradora e criticamente afinada com a reinvenção transgressora de si mesma como instituição formadora de seres individualizados: Edgar Morin, Ivor Goodson e Rudolf Steiner.

O modo organizativo ou, a organização reveste-se de relevância tão grande que o Morin (2008. P. 87) a concebe, metaforicamente, como um dos pilares de sustentação de seu sistema teórico, ou seja, ela é considerada como um dos conceitos - ou ferramentas teóricas, quase soberanas nessa construção, pois poucos são aqueles que suportam o encargo de regente de uma orquestra de $n$ instrumentos dispersos; e é neste sentido que o autor diz:

A organização é minoritária, seguramente. Mas todo soberano é minoritário e solitário. A organização dispõe do verdadeiro poder cósmico: do princípio físico da seleção natural. Na verdade ele se automantém resiste às eventualidades, se autodesenvolve. 
A centralidade na forma de organização curricular é silenciosamente poderosa e não-inocente; tendo antecedentes e desdobramentos diversos, sob diferentes aspectos, pois ao presidir o conjunto de ações decisórias precede, acompanha, coordena e desencadeia todo o processo de gestão dos conhecimentos e experiências de gerações e gerações marcando, profundamente, suas subjetividades, pois a ordem que institui atuará, diretamente, sobre a visão de mundo, de sociedade, de homem, de educação, de escola dessas gerações.

Ao encontro dessas ideias tem-se a refinada contribuição de Goodson (2007a, p. 26), que se dedica integralmente as questões do currículo e suas distintas dimensões e articulações. Observa-se através dessa obra sua marcante formulação sobre a concepção do professor e a defesa de que as políticas públicas invistam em reestruturações que tenham um forte apelo ao atendimento da subjetividade e da criatividade docente, para que se obtenham mudanças no âmbito do sistema escolar. E Nisso, inscreve a perspectiva de estudos, pesquisas e práticas de orientação autobiográficas. E conclui:

Partindo da prescrição autoritária e do aprendizado primário para uma habilitação narrativa e o aprendizado terciário transformaria nossas instituições educacionais e as faria concretizar suas promessas anteriores de contribuir para mudar o futuro social de seus alunos.

Tanto na perspectiva moriniana quanto na goodsoniana, encarar as dificuldades de um currículo totalizante parece ser estratégia-chave para romper, de uma vez por todas, com a fragmentação. Esta óptica, em particular, advoga a necessidade de um currículo como narração, dando vez, voz e espaço a história de vida dos sujeitos envolvidos do processo ensino aprendizagem, sobre o que Goodson (2007a, p. 250) diz:

(...) ver a aprendizagem como algo ligado a história de vida é entender que ela está situada em um contexto, e que também tem história - tanto em termos de histórias de vida dos indivíduos e histórias e trajetórias das instituições que oferecem oportunidades formais de aprendizagem, como de histórias de comunidades e situações em que a aprendizagem informal se desenvolve.

A formulação teórica produzida por Rudolf Steiner é também marcada por um forte apelo à subjetividade e criatividade humana, onde é imperiosa a necessidade de conhecer - de modo totalizante, o homem em desenvolvimento para conseguir 
abstrair princípios adequados a sua educação, com destaque para o conhecimento na natureza oculta do ser humano - omitido em todas as abordagens antecedentes, que se fixam apenas nas relações do homem consigo mesmo, com a outros homens e com a natureza, omitindo a dimensão espiritual - que a ciência espiritual (Antroposofia) tem por objeto, dizendo respeito ao "corpo vital ou etéreo" ou "força vital".

Segundo Steiner (1996, p.13), do ponto de vista histórico, foi o materialismo que, a partir do século XVIII e primeira metade do século XIX, excluiu e esvaziou a ciência dessa dimensão: em suas palavras: "Os cientista passaram a dizer que um ser vivo se estrutura exatamente como o faz um ser dito inanimado; que as forças reinantes no organismo são as mesmas que atuam no mineral - apenas de maneira mais complicada, pois formam uma estrutura complexa”.

Assim, a necessidade de resgatar uma perspectiva efetivamente totalizante, inclusiva, que considerasse distintas dimensões constitutivas da vida em geral e do ser humano, em especial, é o que justifica a proposta steineriana de educação e de escolarização, prescrita através da Pedagogia Waldorf. Segundo o autor, a dimensão espiritual é parte integrante fundamental do ser humano. Este possui quatro dimensões básicas, que o constituem como tal: (1) corpo físico; (2) corpo etéreo ou vital. (3) corpo astral ou das sensações e (4) corpo do "eu".

Com base em todos os elementos da Antroposofia, advogados por Steiner (1996, p.45), este solicita que não se negue, por muito tempo mais, "ao movimento antroposófico, um consentimentos compreensivo" para ser incluído como campo de estudos de quem pretenda ser professor.

O currículo, sendo um código estruturante, organizacional, para qualquer proposta pedagógica, empresta ou dá forma específica, para subsidiar como operacionalizar tal proposta. Assim, destaca-se neste tópico da formulação antroposófica de Steiner (1988, p.133) as quatro recomendações fundamentais para fomentar um projeto pedagógico.

a) Que o projeto escolar goze da ampla aceitação geral no contexto da escola, de modo a torná-lo um projeto coletivamente compartilhado;

b) Que todos os profissionais envolvidos, diretamente, no projeto passem, previamente, por treinamento específico, de modo a dominar a formulação teóricometodológica da Antroposofia (ciência espititual); sendo exigido ao professor conhecimento profundo da formulação teórica antroposófica;

c) Que a experiência curricular ocupe tempo integral. E que o currículo ideal - seja conjugado com concessões ao currículo regulamentado pelo poder 
público, uma vez que a escola não é ilha apartada de uma sociedade politicamente estruturada;

d) Que o período vespertino seja destinado a atividades de educação física e euritmia (marcha cantada) e o matutino seja dividido pelas demais áreas de conhecimento, devidamente dialogais entre si.

Nas formulações curriculares de Steiner (1996, p. 39) foi incluída como básica a ideia-força de que o educador dê atenção às "forças anímicas", através das quais o processo educativo acontece, quais sejam: pensar, sentir e querer.

Cumpre assinalar que em vários pontos a proposta pedagógica de Steiner possui forte identificação com a proposta pedagógica libertária, bem como com a proposta de autoformação, em termos de princípios educativos que comumente advogam. Tal associação é corroborada na enunciação de Pey (2000, p. 67) que diz:

A mentalidade anarquista tem sido autoformadora. Sempre se tem distanciado de confundir aquisição de conhecimentos com disciplinas escolares, em classes acadêmicas, em instituições piramidais. Cada vez que os anarquista fizeram funcionar escolas, inventaram para elas uma prática educativa que fez revolucionar as estruturas e o funcionamento escolar.

Referida similaridade é ratificada pela mesma autora que afirma no grupo de autoformação tudo é contingencial, determinado pelo contexto: estudar, ensinar, aprender, estabelecer relações, pensar alto, fazer junto desejar coletivamente. Para Pey (2000, p. 70-71) os grupos de autoformação assemelham-se a "uma multiplicidade de subjetividades, pulsando ao sabor dos acontecimentos da convivência" exigindo atenção focal nos acontecimentos da própria vida, da própria história, das experiências e mais:

(...) estar atento aos acontecimentos, tentando aprender com eles, e perceber o quanto se pode avançar em sabedoria, quando o grupo é capaz de, revisitando as memórias individuais, construir memórias coletivas, fazer dialogar seus saberes entre si e com aqueles que, escrevendo, foram capazes de construir conhecimentos com fragmentos de suas autobiografias.

Não é sem razão que, também, Goodson envereda pela articulação com as possibilidades pedagógicas das histórias de vida!

Cumpre lembrar que a proposta goodsoniana de "currículo como narração" 
tem investido em experiências relativas a autoformação curricular, a ecopedagogia, multiculturalismo e a histórias de vida; dialogando com categorias integrantes do pensar complexo, integrado, a partir de vozes convergentes, cumpre avançar para uma práxis educativa manifesta em vivências, afinal, segundo o artigo 11 da Segunda Carta da Transdisciplinaridade (1994):

(...) uma educação autêntica não pode privilegiar a abstração no conhecimento. Deve ensinar a contextualizar, concretizar e globalizar. A educação transdisciplinar reavalia o papel da intuição, da imaginação da sensibilidade e do corpo na transmissão dos conhecimentos.

Essa exigência de criatividade será possível se trabalhada, contemporaneamente, no âmbito do currículo como narração, afinal nos adverte Morin (2002, p.27)

\begin{abstract}
(...) há cerca de quarenta anos estamos diante de um mundo singularmente novo. E temos que nos situar neste mundo, do qual não passamos, evidentemente, de uma minúscula parte. Mas o paradoxo é que, se essa parte se encontra num todo gigantesco, o todo se encontra, ao mesmo tempo, no interior dessas parcelas ínfimas que nós somos, pois aquilo que é a coisa mais exterior a nós mesmos, isto é, as partículas que se constituíram no início do universo, esses átomos que se formaram nas estrelas, essas moléculas que se constituíram na Terra ou em outro lugar (..).
\end{abstract}

\title{
O projeto político pedagógico da Escola Waldorfiana
}

O Projeto Político-Pedagógico (PPP) constitui um denso documento nomeado como Proposta Educacional das Escolas Waldorf no Brasil foi elaborado em 1998, de modo participativo e solidário por um grupo de sete educadores integrante de escolas pertencentes à Federação Escolas Waldorf no Brasil. No documento constatou-se cinco seções abordadas: (a) finalidades da proposta educacional; (b) ideário institucional da proposta educacional; (b) ideário institucional; (c) Formação de professores Waldorf - Curso Normal; (d) Trabalho social da instituição; (e) formas de acompanhamento da proposta educacional Waldorf.

Trata-se de proposta aberta a distintas possibilidades de percursos curriculares, mas ainda presa a modelos, sendo a mais notória comprovação do tamanho do desafio de romper com o instituído, cuja expressão e face amis visível reside no currículo prescrito de que nos fala Goodson (2007b, 2008) e Bauman (2008, p. 177) - que adverte da necessidade de se romper com antigos formatos escolares que "talvez seja 
o maior desafio que os filósofos da educação (...) já encontraram na história moderna de sua disciplina”. Tal Projeto Político-Pedagógico (PPP) foi objeto de análise no livro organizado por Vasconcelos (2015).

\section{Narrativa de cenas vicárias presenciadas no currículo em ação}

Estudos e pesquisas que abordam a escola, nos últimos trinta anos, assinalam a persistência e a hegemonia de um formato tipológico nascido no século XVII, no qual predomina - direta e indiretamente, uma linha de trabalho didático-pedagógico radicalmente fragmentária, alheia a desafios e demandas do mundo contemporâneo complexo, como se dele a instituição escolar não fizesse parte. Neste cenário, as escolas que conseguem driblar a lógica predominante e passam a empunhar a bandeira da complexidade e inter-transdisciplinaridade, acabam sendo assediada, cortejadas por educadores interessados em observar tais iniciativas pioneiras de escolarização para ver de que maneiras elas romperam com o modelo dominante instituído de escola, em favor do inovador. Este foi o caso do grupo de pesquisadoras interligadas ao LEPTRANS/UFRRJ que, após estreitar relações investigativas com uma escola waldorfiana, decidiu ampliar a visibilidade a essa instituição, evidenciando suas distintas dimensões no modo de ser escola inovadora. Neste espaço serão feitas narrativas de cenários presenciados pelas pesquisadoras, em momentos de visita durante o período de aulas. Selecionamos alguns aspectos, começando por uma descrição geral da localização e dos prédios que abrigam a escola waldorfiana e, posteriormente, serão feitas exposições breves de acontecimentos ou cenas típicas de quem rompeu com a escola tradicional em favor do novo.

\section{O cenário e os prédios que abrigam a Escola Waldorfiana}

A unidade escolar waldorfiana sediada em Nova Friburgo é sediada em extensa área verde, bastante arborizada, entrecortada por um riacho de águas transparentes, cujo barulhinho típico por sobre as pedras e pedregulhos é ouvido em qualquer um dos quatro prédios que formam o complexo escolar - que se distribuem espacialmente a norte, sul, leste e oeste do terreno. Não são prédios suntuosos, são apenas e tão somente diferentes do modelo padrão. Todos conjugam alvenaria e madeira e têm finalidades de ocupação diferentes. Do ponto de vista do traçado arquitetônico cada um deles mantém-se adequado a faixa etária das crianças que neles mais circulem. Ao passar do portão de entrada se escolhe o caminho a seguir, em função de onde se quer chegar, ou seja, o percurso é ramificado, de modo que não há uma trajetória 
linearmente traçada, a ser seguido por todos. Assim, ao circular pela escola você encontrará um prédio destinado a educação infantil - estrutura de uma colmeia, com seis casulos, em cada um dos quais são abrigadas no máximo 10 crianças, desfrutando do conforto de um mini-apartamento, todo feito para suprir as necessidades delas, de modo agradável. Outro prédio, o destinado a primeira a quarta séries, cuja divisória oportunizam a livre circulação entre as salas, cuja funcionalidade permite que aquele espaço seja vestido das estações do ano- temas geradores do currículo escolar waldorfiano, com liberdade de circulação das crianças que, ali, têm a sua disposição, em locais apropriados, folhas de papel de tamanhos e tipos distintos, diversos conjuntos de lápis de distintas cores, estojos de tinta de cores variadas, flauta doce - uma de cada aluno e dois ou três instrumentos musicais de corda e percussão. O terceiro prédio é destinado aos alunos maiores em atividades diversificadas, realizadas em grupos usando mesas grandes para trabalhos em grupos, tais como pintura, tecelagem, desenho, música, entre outras. Finalmente, a Brinquedoteca o menor dos quatro prédios, sendo constituída por uma única sala pequena e aconchegante, com cantinhos definidos para a coordenadora e os brinquedos ligados a cada uma das áreas de conhecimento: Comunicação e Expressão, Estudos Sociais, Ciências e Matemática, sendo todo o material de fácil acesso as crianças. Cada prédio é ladeado por acesso a áreas de lazer que mais imitam os antigos quintais da casa dos avós, por onde as crianças circulam e dispões de balanços, perna de pau, tabuleiro de areia, miniparque infantil e árvores nas quais os pequenos sobem e descem, velozmente, sem parar.

\section{Acontecimentos e cenas da Escola Waldorfiana}

Dentre as cenas marcantes que conferem fortes indícios de rompimento com a escola tradicional, destacam-se quatro delas: (a) o rito inicial de atividades diárias da escola; (b) as atividades em cada sala; (c) o recreio, o lanche e o retorno; (d) a saída com saudade.

(a) $\mathrm{O}$ rito inicial de atividades diárias da escola. $\mathrm{O}$ dia inicia com a recepção de cada professora aos seus alunos em área comum da escola, para festejar o dia, cantando, dançando, tocando. A temática é variada, e cada turma decide qual a sua para aquele dia, incluindo cantigas pedagógicas, cantigas de roda, poesia, saudação, parabéns para os aniversariantes, sempre usando o próprio corpo (eurritmia) para marcar o tempo. Enfim, é o momento do encontro geral de toda a escola trocar experiências. Parece que faz parte das atividades em sala de aula planejar, talvez ensaiar, esse momento do dia seguinte.

(b) As atividades em cada sala. Concluído o momento do encontro da escola, 
cada professora se encaminha para a sua sala com os seus alunos e ali se planeja, em conjunto, o cronograma do dia - planejamento participativo de curto prazo. O tema central, entretanto, é a estação do ano que, aliás, impregna o espaço da sala de aula e todas as atividades curriculares. Chama a atenção que os alunos comecem a atividade do dia pegando uma folha de papel e desenhando a capa das atividades do dia, o que lhes torna exímios desenhistas. A partir daí a aula é desenvolvida de modo participativo, mas ordeiro, ou seja, sem tumultuo.

(c) O recreio, o lanche e o retorno. Ante o toque de sineta, as crianças são liberadas para ir ao refeitório ou a área verde, contígua a sua sala, sem gritos nem bagunça. Foi notória a preferência das crianças por subir e descer árvores: os olhos dos que conseguem sem embaraços é deslumbrante para quem os observa. O recreio termina quando a professora os chama na porta de sua sala de aula, de um modo muito peculiar e interessante: com a flauta, tocando uma música suave, como que chamando a que entrem e passem a se concentrar em outra atividade. No conjunto, pareceu que o esforço é mesmo o de derrubar as fronteiras entre os campos de saber e realizar experiências curriculares integradas, o que marca essa escola inovadora com os traços da interdisciplinaridade. É assim que as atividades diárias prosseguem a sua rotina "sem rotina desagradável" até a hora do almoço, do lanche vespertino e de sair da escola.

(d) A saída com saudade. Ao soar a sineta, a expectativa de cansaço da maioria das crianças mostra-se infundada, pois muitas delas dizem que não querem ir para casa e já estão com saudade da escola, antes de dela sair. Este parece ser um sintoma decisivo de que a experiência escolar vivida é de satisfação, contrapondo-se ao que é comum entre crianças que dizem não gostar da escola.

\section{Considerações conclusivas}

Para as pesquisadoras o trabalho realizado, efetivamente, ultrapassou o objetivo da pesquisa, pois a análise dos três projeto teóricos eleitos pelo grupo pelas possibilidades fomentadas de romperem com a escola fragmentária, dissociada de interesses e necessidades mais amplos do que o chão da escola ultrapassada pelo novo contexto mundial, convergem para uma escola integrada/integradora e criticamente afinada com a reinvenção transgressora de si mesma como instituição formadora de seres individualizados.

Se a disciplinaridade hegemônica na organização curricular acabou, em seu movimento histórico, gerando uma escola que se encontra em séria e prolongada crise - que 
a marca como instituição decadente, desajustada dos interesses e das necessidades sociais contemporâneos, nas quais - pesquisas denunciam e revelam que as crianças pouco aprendem do conteúdo formalmente veiculado nas salas de aula e que esta instituição já "está obsoleta", cega, surda e muda aos reclamos da soberania do mercado-rei, nossa aposta ou hipótese de trabalho parece confirmada. Através do exposto, é possível reverter o quadro de descontentamento com a lógica organizacional fragmentária própria da disciplinaridade, em favor de práticas curriculares integradas de escolarização intertransdiciplinar, desde que seja dada visibilidade mais ampla a experiências afinadas com a natureza epistemológica dos projetos aqui trabalhados, sobretudo a partir de estudos, pesquisas e debates acerca de experiências escolares hoje minoritárias, marginais, carentes de fomento e amplificação das vozes que falem a seu favor, a exemplo da proposta de escola Waldorf com a qual estamos em interação dialógica.

\section{Referências}

ANDERSON, P. Balanço do neoliberalismo. Emir Sader e Pablo Gentili (Orgs). Pósneoliberalismo: as políticas sociais e o estado democrático. Rio de Janeiro: Paz e terra, 1995.

BAUMAN, Z. A sociedade individualizada: vidas contadas e histórias vividas. Rio de Janeiro: Zahar, 2008.

CRESWELL, J. W. Projeto de pesquisa - métodos qualitativo, quantitativo e misto. Porto Alegre; Artmed \& Bookman, 2010.

CARTA DA TRANSDISCIPLINARIDADE. I Congresso Mundial de Transdisciplinaridade. Arábia/Portugal, 1994. Disponível em http://cetrans.com.br/wp-content/ uploads/2014/09/CARTA-DA-TRANSDISCIPLINARIDADE1.pdf.

Acesso 10/04/2016

DENZIN, N. K \& LINCOLN, Y. O planejamento de pesquisa qualitativa teorias e abordagens. Porto Alegre: Artmed \& Bookman, 2007.

HOBSBAWM, E. O breve século XX. 1914-1991. São Paulo: Cia da Letras, 1996

HÜBNER, M. M. Guia para a elaboração de monografias e projetos de dissertação de mestrado e doutorado. São Paulo: Pioneira, 2004. 
IANNI, O. Teorias da globalização. Rio de Janeiro: Civilização Brasileira, 1995

JAMESON, F. Conversas sobre a nova orden mundial. Robon Blackbum (Org.). Depois da Queda. Rio de Janeiro: Paz e Terra, 1993.

GOODSON, I. As Políticas do conhecimento: vida e trabalho docente entre saberes e instituições. Goiânia: Cegraf, 2007a.

12, n. 35, 2007b.

Currículo, narrativa e futuro social. Revista Brasileira de Educação, v.

. As políticas de currículo e de escolarização: abordagens históricas. Petrópolis; Vozes 2008.

MORIN, E. O método 1: a natureza da natureza. Porto Alegre: Sulina, 2008.

Complexidade e ética da solidariedade. In: Gustavo de Castro (Org.). Ensaios de complexidade. Porto Alegre: Sulina, 2002.

PEY, M. O. Constatações de uma professora infame. In: LUENGO, J. M. et al (Orgs). Pedagogias libertárias: experiências hoje. São Paulo: Imaginário, 2000.

SEMLER, R., DIMENSTEIN, G. e COSTA, A. C. G. Escola sem sala de aula. Campinas, Papirus, 2004.

STEINER, R. A estruturação do ensino baseado no conhecimento do homem. México; Ed. Antroposófica, 1970.

A educação da criança segundo a ciência espiritual. Ed. Antroposófica, 1996.

TRIVIÑOS, A. N. S. Introdução à pesquisa em ciências sociais: A pesquisa qualitativa em educação. O positivismo, a fenomenologia, o marxismo. SP: Atlas, 2007.

VASCONCELOS, H. C. (Org) Escola waldorfiana sob a óptica de uma pesquisa intertransdisciplinar. Vila Velha-ES: Above Editora, 2015.

Recebido em: 12 abril 2016.

Aceito em: 21 abril 2016. 